\title{
Direito Humano a um Meio Ambiente Saudável: uM DiREITO RECONHECIDO POR TRIBUNAIS INTERNACIONAIS? ${ }^{1}$
}

\section{Thomaz Francisco Silveira de Araujo Santos ${ }^{2}$}

\section{INTRODUÇÃO}

Este artigo se concentra em descobtir se há ou não um direito humano independente e universal ao meio ambiente saudável, e se tal direito pode ser reconhecido e ter seu cumprimento exigido por tribunais internacionais. As principais fontes de direito internacional também serão analisadas para averiguar se tal direito pode ser encontrado em algum tratado multilateral ou convenção ou se na verdade trata-se de um direito costumeiro internacional em desenvolvimento.

Depois de uma breve análise das chamadas "gerações de direitos humanos" tentarei definir esse direito no campo teórico e identificar quão universal e independente ele de fato é. $\mathrm{Na}$ segunda parte do artigo me concentrarei em como os diversos tribunais internacionais têm tratado danos ambientais que possam acarretar violações a direitos humanos e se esses tribunais seguem uma linha clara de definição de quais danos consistiriam em violações ao alegado direito humano ao um meio ambiente saudável.

1 Trabalho originalmente apresentado em inglês para aprovação na disciplina de "International Environmental Law", sob orientação do Professor Stephen Kass, cursada na Pace Law School, White Plains, NY, no semestre de 2003/02, como parte do programa de intercâmbio FIPSE-CAPES "Responsabilidade Ambiental".

2 Bacharel em Direito na UFRGS, bolsista do programa FIPSE-CAPES no semestre de 2003/02, na Pace Law School, White Plains, NY. 


\section{PARTE I: BASE TEÓRICA PARA UM DIREITO HUMANO A UM MEIO AMBIENTE SAUDÁVEL}

\section{1 "Gerações" de Direitos}

Quando falamos de direitos humanos, geralmente são eles definidos em termos de gerações: os direitos civis e políticos, ou direitos de liberdade, como a liberdade de expressão e o direito a voto são considerados direitos de "primeira geração", uma vez que foram eles os principais objetos de luta das revoluções francesa e americana no século XVIII e foram os mesmos consagrados nas Constituições desses países como maiores conquistas das respectivas revoluçōes; os direitos econômicos, sociais e culturais são considerados de "segunda geração", os direitos de igualdade, como, por exemplo, o direito a saúde, e eles refletem valores e idéias que começaram a ganhar força nas primeiras décadas do século XX, em que os ideais do "Estado de Bem Estar Social" estavam em voga em países como os Estados Unidos da América de Franklin Delano Roosevelt; e recentemente tem havido diversas discussões sobre a chamada "terceira geração" de direitos que seriam os de solidariedade, ${ }^{3}$ que só poderiam ser conquistados e efetivados pelo esforço solidário dos Estados, assim como o direito a um meio ambiente saudável. ${ }^{4}$ Direitos como o direito a um meio ambiente saudável e o direito ao desenvolvimento não podiam ser acomodados nas duas outras gerações, uma vez que esses direitos necessariamente afetam mais grupos de pessoas do que indivíduos propriamente ditos. ${ }^{5}$

Portanto, esse brevíssimo apanhado geral da história dos direitos humanos nos mostra que o direito a um meio ambiente saudável estaria inserido num sistema geral de direitos humanos. Contudo, não nos diz como identificar quando uma violação a esse direito de fato ocorreu. Ainda, não sabemos ao certo a natureza desse direito no Direito Internacional Público, se consiste numa regra de direito costumeiro ou num princípio geral de direito, para citar os termos do artigo 38 do Estatuto da Corte Internacional de Justiça. Mas o mais importante é que não sabemos como uma eventual violação a esse direito poderia ser tratada por um tribunal. Por tais razões é necessária uma abordagem teórica mais detalhada para esse direito, para tentar encontrar sua definição dentro do Direito Internacional Público. Em seguida, casos de diversos tribunais internacionais serão analisados para que possamos averiguar como tais tribunais identificam e medem as violações a tal direito.

3 Percebe-se que essa visão clássica das "gerações" reflete os próprios ideais da Revolução Francesa de 1789 (liberdade, igualdade e fraternidade), sendo que constitucionalistas modernos atacam essa divisão acusando-a de ser estanque e ultrapassada. Para uma discussão mais aprofundada da atual situação dos direitos humanos no cenário internacional, ver CANÇADO TRINDADE, Antônio Augusto. Tratado de Direito Internacional de Direitos Humanos, v. I, Porto Alegre: Sérgio Antonio Fabris Editor, 1997.

4 ATAPATTU, Sumudu. "The Right to a Healthy Life or the Right to Die Polluted: The Emergence of a Human Right to a Healthy Environment under International Law", 16 Tul. Envtl. L. J. 65, p.110 (2002).

5 ALSTON, Phillip. "A Third Generation of Solidarity Rights: Progressive Development or an Obfuscation of International Human Rights Law?", 29 Neth. Int'l L. Rev 307, p. 317 (1985). 


\subsection{Fontes do Direito Internacional Público: o Artigo 38 do Estatuto da Corte Internacional de Justiça (CIJ)}

Além de estabelecer a jurisdição da Corte para casos internacionais o Estatuto também determina quais são as fontes de Direito Internacional Público para os fins da Corte, e diversos internacionalistas têm considerado esse artigo do Estatuto como uma definição do que é o direito internacional. ${ }^{6} \mathrm{O}$ Estatuto diz que as fontes do Direito Internacional Público, em ordem de importância, são: tratados e convenções internacionais estabelecendo regras expressamente reconhecidas pelos Estados da disputa em questão; direito costumeiro internacional; princípios gerais de direito reconhecidos por nações civilizadas; e, como fontes subsidiárias, decisões judiciais e trabalhados e os trabalhos de renomados doutrinadores do Direito Internacional Público?

No que diz respeito a tratados, eles são vistos geralmente como acordos internacionais feitos entre Estados, na forma escrita e sujeitos ao Direito Internacional Público. ${ }^{8}$ Tais tratados devem ser acordados pelos Estados de boa-fé $e^{9}$ e podem ser considerados nulos se momento de sua conclusão o tratado estiver em conflito com normas peremptórias de Direito Internacional Público. ${ }^{10}$ Portanto, se houvesse disposições em um tratado que versassem sobre o direito humano a um meio ambiente saudável isso seria considerado direito internacional público como contido num tratado. Contudo, para que um direito seja considerado um direito humano ele deve ser aceito universalmente pela comunidade internacional, como o que ocorre com os direitos à vida e à liberdade de expressão. No caso do direito humano a um meio ambiente saudável ele ainda não foi explicitamente reconhecido por algum tratado multilateral ou convenção internacional que obriguem os países-membro do respectivo tratado ou convenção. ${ }^{11}$

Talvez a fonte mais adequada na qual poderíamos enquadrar esse direito seja a do direito internacional costumeiro. Os requisitos básicos para que haja uma regra costumeira são a prática generalizada e consistente dos Estados e a noção de que essa prática deveria ser seguida porque ela decorre de uma obrigação legal internacional ("opinio juris"). ${ }^{12}$ Logo, a mera prática continuada dos Estado pode ser desconsiderada para efeitos de um costume internacional se todos os países são livres para agir de forma diferente, uma vez que não é esperado que eles ajam de acordo com tal prática. No caso do direito costumeiro internacional não é necessário que todas as nações sigam a mesma prática, pois a generalidade complementa

6 LEE, John. "The Underlying Legal Theory to Support a Well-Defined Human Right to a Healthy Environment as a Principle of Customary International Law", 25 Colum. J. Envtl. L. 283, p. 291 (2000).

7 Estatuto da Corte Internacional de Justiça, art. 38, $\$ 1^{\circ}$, de 26 de junho de 1945.

8 Convenção de Viena Sobre Direito dos Tratados, art. 2.1(a), de 2.3 de maio de 1969.

9 Id., art. 26

${ }^{10}$ Id. art. 53

1125 Colum. J. Envtl. L. 283, pp. 306-7

${ }^{12}$ BROWNLIE, Ian. Principles of Public International Law, $5^{a}$ ed., 1998, Oxford University Press, p.7 
a univetsalidade, e a generalidade na prática dos Estados pode ser encontrada, por exemplo, ao se analisar o sistema jurídico de uma nação e averiguar quantos países internalizaram a alegada regra de direito costumeiro em suas constituições ou quantos deles votaram a favor de resoluções da Assembléia Geral das NJações Unidas que tratem dessa alegada regra costumeira. ${ }^{13}$ Quanto à "opinio juris" a Corte Internacional de Justiça já declarou que os Estados devem agir de uma forma que seu comportamento comprove a crença de que determinada prática é obrigatória para o Direito Internacional Público. ${ }^{14}$

Temos, portanto, duas fontes de Direito Internacional Público em que poderíamos basear o argumento de que o direito humano a um meio ambiente saudável é de fato um princípio reconhecido de direito internacional público. Contudo, em nenhum desses casos o direito foi expressamente reconhecido pela comunidade internacional. ${ }^{15}$ Os únicos documentos internacionais e multilaterais que expressamente reconhecem esse direito não são documentos vinculantes, como as declarações de Estocolmo ${ }^{16}$ e do Rio de Janeiro, ${ }^{17}$ que consagram a idéia geral de que os seres humanos têm direito a vida produtiva e saudável em harmonia com a natureza. No que diz respeito ao direito costumeiro internacional, ainda que num nível regional os Estados tenham feito um esforço de se referirem expressamente a esse direito em tratados e outros documentos internacionais, aparentemente a comunidade internacional não parece disposta a reconhecer o direito humano a um meio ambiente saudável, a não ser que esse direito seja fundamentado por outros direitos legitimamente reconhecidos ${ }^{18}$

Isso não significa, no entanto, que tal direito não será reconhecido pela comunidade internacional: se devidamente apoiado por e fundamentado por outros direitos a ele relacionados o seu reconhecimento pela comunidade internacional ocorrerá muito mais facilmente. Por outro lado, isso significaria que tal direito não seria independente, sempre necessitando que efeitos fossem sentidos em outros direitos para que se considerasse que ele fora violado.

\subsection{Ligações e Convergências}

Se um direito não pode ser estabelecido de forma independente, a ligação contextualizada com um direito reconhecido pode ocorrer. ${ }^{19}$ Basicamente, pode-se analisar

${ }^{13}$ CAREW, Koriambanya S. A. "David and Goliath: The Indigenous People of the Niger Delta, A Smooth Peeble - Environtmental Law, Human Rights and Re-Defining the Value of Life", 7 Drake J. Agric. L. 493, pp.509-10 (2002)

${ }^{14}$ Caso das Atividades Militares e Paramilitares contra e na Nicarágua, CIJ, 1986, par. 98

15 McCLYMONDS, James T. "The Human Right to a Healthy Environment: An International Legal Perspective", 37 N.Y.L. Sch. L. Rev. 583, p. 597 (1992)

${ }^{16}$ Relatório da Conferência das Nações Unidas sobre o Meio Ambiente: Princípio 1, UN Doc A/Conf. $48 / 14$ (1972)

17 Declaração do sobre Meio Ambiente e Desenvolvimento, UN Doc. A/Conf. $151 / 5$ (1992)

${ }^{18} 7$ Drake J. Agric. L. 493, p. 511

1925 Colum. J. Envtl. L. 283 , p. 304. 
como o direito a um meio ambiente saudável está relacionado ou ligado com outros direitos humanos já estabelecidos. A mais óbvia dessas ligações é com o direito à vida, o direito humano mais fundamental, uma vez que a proteção do meio ambiente garantiria a sobrevivência e perpetuação da espécie humana. ${ }^{20}$ Nesse caso, um dano ambiental teria de ser tão grande a ponto de ameaçar as vidas dos membros de todo um grupo. Outra ligação óbvia é com o direito à saúde, que pode ser claramente relacionado ao meio ambiente quando se diz que "todas as pessoas têm o direito ao mais padrão mais alto possível de saúde livre de danos ambientais." ${ }^{21} \mathrm{Um}$ grande dano ambiental que se torne um risco à saúde humana pode também ser considerado uma violação do direito a um meio ambiente saudável. ${ }^{22}$

Há outros direitos que não são tão fundamentais e amplos como o direito à vida e à saúde, mas que também são intensamente afetados por danos ambientais. Os direitos dos povos indígenas estão entre esses direitos, pois certos povos indígenas recebem uma proteção legal especial de sua identidade cultural, sua terra nativa seu bem estar e autodeterminação. ${ }^{23}$ Na verdade essa relação ou ligação pode muito bem ser a mais apropriada, uma vez que os povos indígenas geralmente têm uma co-dependência maior com o meio ambiente do que as comunidades urbanas: para os povos indígenas, a própria terra é a base de sua cultura. ${ }^{24}$ Outra relação possível e recomendável é com o direito ao desenvolvimento sustentável, que já foi declarado pela Assembléia Geral da ONU como um direito humano inalienável. ${ }^{25}$ Ainda que essa seja outra relação importante com o direito a um meio ambiente saudável a Declaração não confirma tal relação, que foi fortemente defendida e enfatizada na Eco $92 \mathrm{e} \mathrm{em}$ outros documentos e conferências das Nações Unidas. ${ }^{26}$ Ainda que haja outras, essas são as relações e convergências com o direito a um meio ambiente saudável que mais facilmente podem ser aceitas pela comunidade internacional.

\subsection{Um argumento a favor da existência de um direito humano a um meio ambiente saudável}

A relação de danos ambientais com direitos humanos tem sido defendida por alguns autores como a melhor forma de garantir que direitos humanos não sejam violados

${ }^{20} 16$ Tul. Envtl. L. J. 65, p. 99.

${ }^{21}$ Comissão de Direitos Humanos das Nações Unidas, Sub-Comissão para Prevenção de Discriminação e Proteção das Minorias, UN Doc E/CN.4/Sub.2/1994/9, princípio 7 (1994)

22 ZIEMER, Laura S. "Application in Tibet of the Principles on Human Rights and the Environment", 14 Harv. Hum. Rts. J. 233, p. 246 (2001).

${ }^{23}$ SCOT'T, Inara K. "The Inter-American System of Human Rights: An Effective Means of Environmental Protection?", 19 Va. Envtl. L. J. 197, pp. 229-30 (2000).

${ }^{24}$ GANZ, Beth. "Indigenous People and Land Tenure: An Issue of Human Rights and Environmental Protection", 9 Geo. Int'l Envtl. L. Rev. 173, p. 174 (1997)

${ }^{25}$ Declaração de Direitos ao Desenvolvimento, art. 1, GA res. 41/128 (1986)

${ }^{26} 25$ Colum. J. Envtl. L. 283, pp. 321-22 
por uma proteção ambiental demasiadamente fraca, chegando a ponto de declarar que a proteção do meio ambiente é um instrumento para a proteção dos direitos humanos, não um fim em si mesmo. ${ }^{27}$ Por outro lado, outros autores declaram que um direito humano universal e independente a um meio ambiente saudável é necessário para se definir uma linha de conduta para os Estados no cenário internacional. ${ }^{28}$

De qualquer forma, essas duas correntes concordam com o fato de que não há uma relação forte e reconhecida ou sequer um direito universal e independente. O esforço deve ser dirigido para a criação de um direito a um meio ambiente saudável, um que seja útil para a para a proteção de interesses ambientais e de propósitos das justiça. ${ }^{29}$ Para determinar se o direito a um meio ambiente saudável deve ser reconhecido como um direito humano um teste de quatro etapas deve ser feito, de acordo com as linhas atuais do direito internacional público.

A primeira etapa seria determinar se esse direito beneficiaria indivíduos reconhecidos. Depois disso, uma segunda etapa seria que os proponentes desse direito deveriam demonstrar que sua demanda não seria adequadamente satisfeita a não ser que esse direito fosse proporcionado a eles, e não outras formas mais fracas de proteção em seu lugar. Numa terceira etapa, os proponentes deveriam provar que as partes que têm deveres em virtude desse direito podem ser legitimamente sujeitas a processos para que venham a cumprir esses deveres $\mathrm{E}$, finalmente, na quarta etapa, deve-se provar que esse direito é factível dentro das condições institucionais e econômicas existentes. ${ }^{30}$ Tendo demonstrado o que esse direito atualmente é e o que deveria ser do ponto de vista conceitual, na próxima parte analisarei como diferentes tribunais internacionais tratam de casos envolvendo danos ambientais e direitos humanos e qual a abordagem adotada por esses tribunais quanto à natureza do direito violado.

\section{PARTE II: O DIREITO HUMANO A UM MEIO AMBIENTE SAUDÁVELE SEU TRATAMENTO PELOS TRIBUNAIS INTERNACIONAIS}

\subsection{A Carta Africana de Direitos Humanos e dos Povos e a Tragédia Nigeriana}

De todos os documentos e tratados internacionais e regionais de direitos humanos a Carta Africana de Direitos Humanos e dos Povos (ou Carta de Banjul) foi a primeira a

${ }^{27}$ SHELTON, Dinah. "The Environmental Jurisprudence of International Human Rights Tribunals", Linking Human Rights and The Environment, Romina Picolotti e Jorge Daniel Taillant (eds.), University of Arizona Press, 2003, p. 1-2.

${ }^{28} 25$ Colum. J. Envtl. L. 283, p. 338

29 MOWERY, Lauren A. "Earth Rights, Human Rights: Can International Environmental Human Rights Affect Corporate Liability?”, 13 Fordham Envtl L. J. 343, pp. 355-56 (2002)

${ }^{30}$ NICKEL, James. "The Human Right to a Safe Environment: Philosophical Perspectives on its Scope and Justification", 18 Yale J. Int'l L. 281, pp. 288-93 (1993). 
afirmar expressamente que "todos os povos têm o direito a um meio ambiente satisfatório para o seu desenvolvimento". ${ }^{31}$ A Carta ainda enfatiza que os direitos individuais são satisfeitos pela realização dos direitos dos povos, o que mostra um abordagem progressiva em relação aos direitos de solidariedade. ${ }^{32}$ Contudo, a Carta não possui mecanismos para o cumprimento de suas disposições e não consegue criar obrigações legais vinculantes para seus paísesmembro, especialmente devido à ausência de uma Corte Africana de Direitos humanos. ${ }^{33}$ Dessa forma, até mesmo danos ambientais que tenham grande impacto para o homem podem permanecer impunes como o que aconteceu na região do Delta do Rio Niger.

$\mathrm{Na}$ terra dos Ogonis, um distrito na região do Delta do Niger, no sudeste da Nigéria, a empresa Shell tem extraído petróleo desde 1958 e até a presente alcançou um montante de US $\$ 30$ bilhões em petróleo. A magnitude dessas operações é tamanha que elas resultaram no que considerado por muitos como a devastação das águas, terra e ar dos Ogonis. ${ }^{34}$ Entre os problemas identificados em relação à operação as pessoas mencionaram tubos de condução em péssimo estado, águas poluídas, poluição do ar, problemas de drenagem e a impossibilidade de pesca, reflorestamento e agricultura em grandes áreas. ${ }^{35}$ Acidentes freqüentes de poluição por petróleo fizeram com que peixes ingerissem a substância e se tornassem impróprios para consumo, quando não venenosos, e apesar do povo do Delta do Niger estar rodeado de águas, ele tem de importar grandes quantidades de água potável devido ao nível de poluição na área. ${ }^{36}$

Basicamente, a cultura e o modo de vida de todo um povo estão a perigo devido às atividades de uma companhia que foram plenamente apoiadas pelo governo nigeriano. ${ }^{37}$ $\mathrm{Na}$ verdade, o governo prendeu e executou nove ambientalistas que protestavam quanto à maneira pela qual o petróleo estava sendo extraído, depois que a Shell pediu ajuda ao exército nigeriano para lidar com os protestos. ${ }^{38}$ Infelizmente não havia forma de um cidadão nigeriano fazer valer a disposição contida na Carta de Banjul, pois não apenas o seu governo estava apoiando as atividades que resultaram em abomináveis violações de direitos humanos contra os Ogonis, como também não havia uma corte independente e imparcial que pudesse analisar tal caso se ele fosse de fato levado a juízo. Esse triste exemplo nos mostra que não

${ }^{31}$ Carta de Banjul, art. 24, OAU Doc. Cab/Leg/67/3/Rev.5 (1996).

327 Drake J. Agric. L. 493, p. 520.

${ }^{33}$ HODVOKA, Iveta. "Is There a Right to a healthy Environment in the International Legal Order?", 7 Conn. J, Int'l L. 65, 75-76 (1991). Para uma introdução mais detalhada ao Sistema Africano de Proteção dos Direitos Humanos, ver CANÇADO TRINDADE, Antônio Augusto. Tratado de Direito Internacional de Direitos Humanos, v. II, Porto Alegre: Sérgio Antonio Fabris Editor, 1999, pp. 193-225.

${ }^{34}$ EATON, John P. "The Nigerian Tragedy: Environmental Regulation of Transnational Corporations, and the Human Right to a Healthy Environment", 15 B.U. Int'l L.J. 261, p. 266.

${ }^{35}$ Id. pp. 266-67.

${ }^{36} 7$ Drake J. Agric. L. 493, p. 500.

${ }^{37} 15$ B.U. Int'l L.J. 261, pp. 269-71.

${ }^{38}$ Id. p. 270. 
adianta em nada possuir uma carta de direitos humanos perfeitamente escrita e contendo disposições adequadas sobre a violação de direitos humanos por danos ambientais sem que haja as ferramentas adequadas para fazer valer esses mesmos direitos. Esse pecado, infelizmente, foi cometido pela Carta Africana de Direitos Humanos e dos Povos.

\subsection{O Sistema Interamericano de Direitos Humanos}

Ainda que a Convenção Americana de Direitos Humanos não mencione o direito a um meio ambiente saudável em seus artigos, o Protocolo de São Salvador afirma que "todos têm o direito de viver num ambiente saudável (...)"39 e que os "Estados-Parte devem promover a proteção, a preservação e a melhora do meio ambiente." ${ }^{40}$ Os termos podem ser semelhantes aos da Carta de Banjul, mas o Sistema Interamericano permite a exigibilidade dos direitos contidos em suas convenção, tanto por meio da Comissão Interamericana de Direitos Humanos (ou Comissão) quanto por meio da Corte Interamericana de Direitos Humanos (ou Corte). ${ }^{41} \mathrm{Na}$ verdade, antes mesmo do Protocolo de São Salvador ser adotado a Comissão concluiu que o Brasil havia violado o direito dos índios Yanomami a vida, liberdade e segurança pessoal ao não tomar medidas para prevenir o dano ambiental que resultou na perda de vida e de identidade cultural entre os Yanomami. ${ }^{42}$ Mesmo sem conter um dispositivo sobre o direito a um meio ambiente saudável a Comissão pode estabelecer uma ligação entre os direitos dos povos indígenas e o meio ambiente. ${ }^{43}$ Contudo, essa ligação não fez com que a Comissão concluísse que os Yanomami tinham direito a um meio ambiente saudável, e em vez de recomendar o caso à Corte a Comissão simplesmente publicou um relatório recomendando a criação de fronteiras protegendo as terras dos Yanomami e reconhecendo a responsabilidade dos Estados de proteger o patrimônio cultural dos povos indígenas, e não seu direito a urn meio ambiente saudável. ${ }^{14}$

Talvez o caso mais surpreendente do Sistema Interamericano foi o caso da Comunidade Indígena Mayagna contra a Nicarágua ${ }^{45}$ A questão desse caso foi que depois de diversos anos peticionando ao governo da Nicarágua para o reconhecimento de suas terras tradicionais o povo Mayagna se deparava com a possibilidade perder 63.000 hectares de terra para uma companhia madeireira. ${ }^{46} \mathrm{Na}$ verdade, a comunidade ainda estava em negociações

39 Organização dos Estados Americanos: Protocolo Adicional à Convenção Americana de Direitos Humanos na Área dos Direitos Econômicos, Sociais e Culturais, art. 11(1) (1988).

${ }^{40} \mathrm{Id}$, art.11(2).

${ }^{41} 19$ Va. Envtl. L. J. 197, pp. 204-07.

42 Índios Yanomami Indians v. Brasil, Comissão Interamericana de Direitos Humanos. 7615, OEA/ Ser.L.V/II/60 doc. 10 ver. 1 (1985).

4325 Colum. J. Envtl. L. 283, p. 329.

4419 Va. Envtl. L. J. 197, p. 215.

45 A Comunidade Indígena Mayagna de Awas Tingni V. A República da Nicarágua, Corte Interamericana de Direitos Humanos (2001)

${ }^{46}$ ANAYA, S. James. "The Mayagna Indigenous Community and Its Effort to Gain Recognition of Traditional Lands: The Community's Case Before the Human Rights Institutions of the Organization of American States", em Linking Human Rights and The Environment, p. 185-87. 
com o governo quanto a outra tentativa de concessão de terras a outra companhia madeireira, e quando a comunidade soube a respeita dessa segunda companhia o governo já havia lhe dado uma licença permitindo a exploração da área. ${ }^{47}$

Em sua decisão a Corte concluiu que o governo da Nicarágua desrespeitou o direito dos Mayagna ao uso e ao gozo de sua propriedade, enfatizando que dentre as "comunidade indígenas (...) há uma tradição comunitária como demonstrado pela forma comunal de propriedade coletiva de suas terras, (...) não estando centrada no indivíduo, mas sim no grupo e na comunidade." ${ }^{48}$ Além disso, a Corte decidiu que "por não delimitar e demarcar a propriedade comunal, e por autorizar a concessão a terceiros de exploração da terra e dos recursos naturais" naquela área, o governo da Nicarágua estava desrespeitando o direito da comunidade Mayagna ao uso e ao gozo de sua propriedade. ${ }^{49}$

Essa decisão claramente reconhece o direito dos povos indígenas à propriedade tradicional e ao seu uso e gozo. Contudo, o aspecto ambiental da disputa não foi sequer mencionado pela Corte, e nenhuma referência ao Protocolo de São Salvador foi feita. Nesse caso a decisão foi diretamente benéfica à comunidade indígena e indiretamente benéfica ao meio ambiente, uma vez que este não parecia ser a maior preocupação da Corte.

\subsection{A Corte Européia de Direitos Humanos}

Dos três sistema regionais de direitos humanos o da Europa é o único que menciona expressamente o direito a um meio ambiente saudável em nenhum de seus documentos legais. ${ }^{50}$ Ainda, mesmo tendo havido muita pressão o direito a um meio ambiente saudável não foi incluído na versão final do Tratado de Amsterdã, que revisou o Tratado de Maastrich, responsável pela criação da União Européia ${ }^{51}$ Contude, ainda que não haja disposições nesse sentido na Conveção Européia de Direitos Humanos, a Corte pode proceder a uma "interpretação evolutiva" dos termos da Convenção devido a sua linguagem ampla. ${ }^{52}$ Basicamente, a linguagem da Convenção permite à Corte expandir o próprio significado de suas disposições, ${ }^{53} \mathrm{e}$ isso certamente poderia ser usado para a criação de uma jurisprudência ambiental da Corte.

\footnotetext{
${ }^{47}$ Id., p. 187.

${ }^{48}$ Comunidade Indígena Mayagna de Awas Tingni v. A República da Nicarágua, par. 149.

${ }^{49} \mathrm{Id}$, par. 153.

s0 25 Colum. J. Envtl. L. 283, p. 307.

51 Projeto do Tratado de Amsterdã, Comissão Européia, Documento CONF/4001/97 (1997 - o tratado entrou em vigor em $1^{\circ}$ de maio de 1999)

52 ACEVEDO, Mariana T. "The Intersection of Human Rights and Environmental Protection in the European Court of Human Rights", 8 N.Y.U. Envtl. L. J. 437, 446 (2000).

${ }^{53}$ MAHONEY, Paul. "Judicial Activism and Judicial Self-Restraint in the European Court of Human Rights: Two Sides of the Same Coin", 11 Hum. Rts. L. J. 57, p. 60 (1990).
} 
O primeiro caso a reconhecer explicitamente a conexão entre meio ambiente e qualidade de vida foi Powell \& Rayner v. Reino Unido. ${ }^{54}$ Nesse caso os autores eram donos de residências próximas ao aeroporto de Heathrow e alegaram que a poluição sonora criada pelo tráfico aéreo havia violado o seu direito à privacidade do artigo $8^{\circ} \mathrm{da}$ Convenção. ${ }^{55} \mathrm{~A}$ Corte entendeu que a interferência com os direitos dos autores era justificada, dada a necessidade do aeroporto para o bem-estar econômico da comunidade ${ }^{56}$ Esse julgamento foi uma espécie de aviso para possíveis demandas ambientais, uma vez que ilustrou que a Corte seria relutante em aceitar que preocupações ambientais seriam mais importantes que questões econômicas amplas que afetassem toda uma comunidade. ${ }^{57}$

Por outro lado, em Lopez Ostra v. Espanha a Corte decidiu que a operação ilegal de uma instalação para tratamento de esgoto resultou na violação direito de autor à privacidade do artigo $8^{\circ} \mathrm{da}$ Convenção. ${ }^{58} \mathrm{~A}$ Corte avançou mais um passo no reconhecimento da conexão entre danos ambientais e qualidade de vida ao declarar que "uma poluição grave do meio ambiente pode afetar o bem-estar dos indivíduos e impedi-los de usufruir suas casas de tal forma que afetaria adversamente suas vidas privada e familiar, sem, contudo, oferecer riscos a sua saúde." ${ }^{19}$ Esse caso representou a primeira situação em que uma violação da Convenção ocorreu em virtude de um dano ambiental. ${ }^{60}$

No entanto, a manobra mais ousada da Corte até hoje foi sua decisão em Guerra \& Outros v. Itália, quando 40 autores estavam preocupados com o "alto risco" de poluição representado por uma fábrica de químicos e fertilizantes localizada a um quilômetro da vila de Manfredonia. ${ }^{61}$ Além disso, um acidente que causou envenenamento de 150 pessoas por arsênico foi devido ao equipamento de tratamento inadequado, e o governo da Itália não tomou medidas fortes o suficiente contra a fábrica, o que levou os autores a declarar para a Comissão que a ausência de medidas práticas, particularmente para reduzir os níveis de poluição e de perigo de acidentes advindos das operações da fábrica, era uma violação ao direito à vida do artigo $2^{\circ}$ da Convenção. ${ }^{62}$ A Corte, seguindo sua linha de raciocínio do Lopez Ostra, decidiu que a Itália "não cumpriu sua obrigações de garantir o direito dos autores de respeito à vida privada e familiar, violando o artigo $8^{\circ}$ da Convenção.".6.

\footnotetext{
${ }^{54}$ Powell \& Rayner v. Reino Unido, 12 Eur. Ct. H. R. 355 (ser. A) (1990).

${ }^{55}$ Id. par. 362-63.

${ }^{56}$ Id., par. 368.

${ }^{57} 8$ N.Y.U. Envtl. L. J. 437, p. 474.

${ }^{58}$ Lopez Ostra v. Espanha, App. No. 16798/90, 20 Eur. Ct. H.R. 277 (1994).

${ }^{59}$ Id., par. 295.

${ }^{60} 8$ N.Y.U. Envtl. L. J. 437, p. 477.

${ }^{61}$ Guerra \& Outros v. Itália, App. No. 14967/89, 26 Eur: Ct. H.R. 357, 362 (1998).

${ }^{62}$ Id., par. 367.

${ }^{63}$ Id., par. 383.
} 
Portanto, mesmo sem haver dispositivos claros ou expressos sobre quando um dano ambiental seria grave o suficiente para ser considerado uma violação da Convenção, a Corte identificou o direito de viver num ambiente com um mínimo de qualidade e também achou um meio de responsabilizar os Estados pelas atividades perigosas ao meio ambiente praticadas por empresas privadas em sua jurisdição territorial. Contudo, a Corte nunca mencionou expressamente a existência de um direito humano a um meio ambiente saudável.

\subsection{A Corte Internacional de Justiça}

A Corte Internacional de Justiça, ao decidir o caso do Projeto Gabcikovo-Nagymaros, uma disputa quando a danos ambientais no Rio Danúbio, entre a Hungria e a Eslováquia, enfatizou a importância de novas normas ambientais que estavam sendo desenvolvidas no momento e salientou a necessidade dos Estados de levar essas normas em consideração e respeitá-las.$^{64}$ Contudo, a Corte deixou de tratar a questão ambiental e resolveu a disputa entre as partes com base num tratado firmado entre elas em $1977 .{ }^{65}$

Em um voto separado, o Juiz Weeramantry, Vice-Presidente da Corte, declarou que "a proteção do meio ambiente é (...) uma parte vital da doutrina contemporânea de direitos humanos, pois é uma condição sine qua non para diversos direitos humanos, como o direito à saúde e o próprio direito à vida." ${ }^{\prime 66}$ Ainda que não seja um documento vinculantes, esse voto separado serve para mostrar que ao menos um juiz da Corte acredita que o relacionamento dos direitos humanos com o meio ambiente não só existe como também é necessário para uma melhor proteção dos direitos humanos.

\section{CONCLUSÃO}

Se na abordagem teórica da Parte I percebemos que não existe um direito humano independente e universal a um meio ambiente saudável, na análise das decisões judiciais da Parte II observamos que, ainda que o direito esteja expressamente reconhecido em alguns documentos, as decisões não o aplicam da mesma forma e muitas vezes sequer mencionam os aspectos ambientais do caso, como no caso da comunidade Mayagna. Não apenas há uma discrepância entre teoria e prática mas há uma ausência de uniformidade dentro de cada uma delas.

\footnotetext{
${ }^{64}$ Projeto de Gabcikovo-Nagymaros (Hungria v. Eslováquia) 1997 I.C.J 7, par. 140.

${ }^{65}$ McCALLION, Kenneth F; SHARMA, H. Rajan. "Environmental Justice Without Borders: The Need for an International Court of the Environment to Protect Fundamental Environmental Rights", 32 GW Int'l L. \& Econ. 351, 359.

${ }^{66}$ Gabcikovo-Nagymaros, par. 204.
} 
Além disso, quando um dano ambiental é de tal magnitude que pode, por exemplo, pôr em risco o bem-estar de toda uma comunidade as cortes consideram isso uma violação de direitos humanos. Não há métodos ou abordagens claras quanto a isso: quando a corte considerar que o dano é de determinado grau, há uma violação. Essa ausência de certeza sobre o que seria uma violação ao direito a um meio ambiente saudável cria problemas não apenas para as cortes, quando se deparam com um caso do gênero', mas também para futuros autores que não sabem o que esperar da corte. Mais uma vez, como em outros problemas do Direito Ambiental Internacional, caímos no campo da incerteza, tendo muitas vezes apenas a esperança de sairmos desse terrena em busca de terras conceituais mais firmas, em busca da certeza. 